\title{
Volver a nombrar el mundo
}

\section{Naming the World Again}

\author{
JoRGE GUTIÉRREZ REYNA \\ Universidad Nacional Autónoma de México \\ Facultad de Filosofia y Letras \\ jorge_gtz_reyna@hotmail.com
}

You may think at first I'm as mad as a hatter When I tell you a cat must have three different names

T.S. Elliot

La aventura de don Quijote por las polvorientas llanuras de la Mancha comienza con un acto adánico. Imaginemos al hidalgo, ya decidido a convertirse en caballero andante, frente al paisaje desolador de sus establos viejos: allí rumia lentamente su rocín flaco; allá las armas de sus abuelos se oxidan en un rincón. A lo lejos cacarean las gallinas y brincan sonoramente los cencerros. Fundir unas armas relucientes, granjear un poderoso corcel, enamorarse de una princesa, son acciones fuera de sus limitadas posibilidades. Sabe que, así como los cartones y las barras de hierro volvieron celada de encaje el que era morrión simple, volver a nombrar el mundo es el comienzo para transformarlo. Y si algo tiene este hidalgo, son palabras.

Al rocín flaco, pues, lo convierte en Rocinante; Aldonza Lorenzo, la campesina "de quien un tiempo anduvo enamorado" (Cervantes, I, 1: 32), se llama ahora Dulcinea del Toboso; luego de ocho días de sinuosos pensamientos, él mismo viene a llamarse don Quijote de la Mancha. 
En la venta donde finalmente es "armado caballero", bastará añadirle el don a la Tolosa y la Molinera, quienes le ciñeron la espada y calzaron la espuela, para que vengan a ser doncellas las que eran mozas extraviadas (I, 3: 47).

Cuando contemplamos atentamente las criaturas que nos rodean, nos percatamos de que los nombres cotidianos que se les han impuesto incautamente logran apenas aprehender el carácter profundo de sus seres misteriosos. Uno puede labrar la tierra, ir de caza, atender una venta, llamándose fulano o mengana; pero a una doncella, a un caballero, a una princesa, a un corcel, les hace falta un nombre "famoso y de estruendo" (I, 1: 33), "alto, sonoro y significativo" (I, 1: 32), "músico y peregrino y significativo" (I, 1: 33), "significativo y propio" (I, 25: 235). Ese otro nombre no es una máscara, por el contrario, revela aspectos de la realidad que el nombre cotidiano nubla o disimula. Habría que ser muy ingenuo para pensar que las cosas de este mundo poseen una única cara: "Yo sé quién soy... y sé que puedo ser, no sólo los que he dicho, sino todos los Doce Pares de Francia" (I, 5: 59). Cada uno de los aspectos de las cosas de este mundo es susceptible de cristalizar en un nombre diferente: una de las tantas y valiosas lecciones de la obra cervantina.

Lección antiquísima, sobra decir, que Cervantes adquirió a través de siglos de tradición literaria occidental. Ahí están los casos bíblicos: Abrán y Saray pasan a ser Abrahán y Sara (Génesis 17:5, 15); Saúl se transforma en Pablo (Hechos 9:18-20). En la Ilíada, los dioses llaman Janto al río que corre a los costados de Troya, mientras que los hombres, Escamandro. También los caballeros andantes tomaban, como recuerda don Quijote, "algún nombre apelativo" que fuera de acuerdo con sus hazañas y atributos (I, 19: 171-172) o bien, "mudaban los nombres cuando querían o cuando les venía a cuento" (II, 17: 677). Empleados en el Quijote, estos procedimientos cobran, desde un cierto punto de vista, un matiz paródico; pero, desde otro, nos muestran, como ya dijimos, que las percepciones de la realidad son numerosas y que hasta las

1 "En todos estos nombres o cambios de nombres sagrados (o sacramentales), la etimología desempeña un papel primordialísimo, por la razón de que el significado verdadero (originario) puede revelar verdades eternas latentes en las palabras" (Spitzer 1948/2005). 
Aldonzas, dependiendo desde qué ángulo se las mire, pueden bien ser Dulcineas envueltas en un halo de fascinación.

Don Quijote no es el único en la novela que lleva a cabo múltiples rebautismos. Como los gatos de Elliot, además de sus everyday names, los personajes de la novela requieren a name that's particular / a name that's peculiar and more dignified. Cide Hamete, se nos dice, llama a Sancho unas veces Panza y, otras, Zancas; Sancho renombra a don Quijote como El Caballero de la Triste Figura (en la Segunda parte será El Caballero de los Leones) y a su esposa como Juana Gutiérrez, Mari Gutiérrez, Juana Panza y Teresa Panza; el narrador pone a Cardenio los motes de Roto de la Mala Figura, Roto, Caballero de la Sierra y Caballero del Bosque; a Ginés de Pasamonte lo llaman Ginesillo de Parapilla y en la Segunda parte, Maese Pedro. Otros personajes adoptan un nombre con el que puedan inmiscuirse, sin desentonar, en la fantástica realidad de don Quijote: Dorotea se transforma en la princesa Micomicona; Sansón Carrasco, en el Caballero de la Blanca Luna y de los Espejos. Todos, en fin, comparten con don Quijote ese afán de hallar un nombre "significativo" y "propio". 2

Aunque la mayoría de los personajes y el propio narrador tengan un trato de la palabra similar, el único a quien se considera irremediablemente loco es don Quijote. El acto de volver a nombrar el mundo que éste emprende revela aspectos de la realidad que escapan a la percepción de los sentidos. El aspecto de Cardenio que se materializa en el apelativo de "Caballero del Bosque" es observable; no así el llamar "yelmo de Mambrino" a la bacía de barbero.

Desde el encuentro con las dos mozas a la puerta del ventillo, "el hidalgo trastornado choca, en su quimera caballeresca, con la realidad ambiente; una realidad vulgar, hecha de circunstancias humildes, casi naturales en su elementalidad, tradicionales en todo caso" (Ayala: XXXVIII). Ese choque ocurre a causa de la palabra. En la mente de don

${ }^{2}$ Los nombres propios se hallan mayormente sujetos a la polionomasia cervantina pues, "siendo como son por naturaleza intraducibles, participan más del aspecto misterioso del lenguaje humano" (Spitzer 1948/2005). Pero también las cosas en el Quijote se miran reflejadas en los pedazos de un espejo roto: "un pescado que en Castilla llaman abadejo, y en Andalucía bacallao, y en otras partes curadillo, y en otras truchuela" (I, 2: 38). 
Quijote tiene sentido que su rocín sea corcel y su vecina, una princesa. Pero qué discordantes son esos rebautismos, esos otros nombres, con la realidad percibida por los ojos: "Cada cual ve poco más de lo que lleva dentro" (Salinas 1958/2005). Las mozas, "como se oyeron llamar doncellas, cosa tan fuera de su profesión, no pudieron tener la risa" (Cervantes, I, 2: 37; las cursivas, aquí y en todos los casos, son mías); al recibirlo, "pensó el huésped que el haberle llamado castellano había sido por haberle parecido de los sanos de Castilla, aunque él era andaluz" (I, 2: 38); al oír las alabanzas de Rocinante, "mirole el ventero, y no le pareció tan bueno como don Quijote decía, ni aun la mitad" (I, 2: 39); "cuando Sancho oyó llamar a la bacía 'celada', no pudo tener la risa" (I, 21: 191).

Del choque entre la realidad percibida por el hidalgo loco y el resto de los personajes brotan híbridos lingüísticos, nuevos nombres en los que "el perspectivismo de Cervantes" cristaliza "en una formación lingüística bifocal" (Spitzer 1948/2005). Es el caso de las semidoncellas, de los concertados disparates, del famoso baciyelmo y, en cierto modo, también el de Lela Marién. En palabras de Margit Frenk (33), el narrador en ocasiones "se da el lujo de mezclar la visión de don Quijote con lo que podemos llamar 'su propia perspectiva'". Cito, por poner un ejemplo, el pasaje de los frailes benedictinos. El narrador no dice, como otras veces, "vio venir don Quijote..." o "eran dos monjes que a don Quijote le parecieron..."; se ahorra ese paso y mezcla su realidad con la del protagonista: "asomaron por el camino dos frailes de la orden de San Benito, caballeros sobre dos dromedarios" (I, 8: 79). El lector, a través de las palabras, ve ambas cosas: las mulas y los dromedarios, así como ve también los molinos y los gigantes, el yelmo y la bacía... En ese nivel de realidad, suma verbal en la que se conjuntan las percepciones de los personajes y el narrador, transcurre gran parte del Quijote.

Las percepciones de la realidad son tantas que no pueden abarcarse en su totalidad. Tampoco los nombres en las que éstas se cristalizan: above and beyond there's still one name left over / and that is the name that you'll never will guess. Además de los que logramos ver, hay otros nombres que Cervantes deja en el tintero. Esas omisiones pueden llegar a ser tan significativas como lo que se halla explícitamente dicho. Me cuesta trabajo creer, por ejemplo, que los nombres de Dorotea y Cardenio, 
tan bucólicos, aparezcan en el acta de bautismo de estos personajes: ¿y si allí se leyera Juana y Sebastián? ¿Cómo se llamaba Rocinante cuando no era sino una bestia de trabajo? Y lo más sorprendente, ¿cómo se llama el mismo don Quijote? ¿Cuál es el nombre "real", si existe tal, de nuestro hidalgo? No importa: "De principio a fin, y pese a sus últimas fantasías, el maravilloso personaje de Cervantes fue lo que quiso ser: don Quijote de la Mancha" (Frenk: 47). Nunca sabremos tampoco si Pero Pérez, cuyo nombre aparece mencionado una sola vez en la Primera y Segunda partes de la novela, fantaseaba, mientras charlaba con sus amigos acerca de Amadís o don Galaor, con ser algún caballero y llevar un nombre que lo presidiera en sus andanzas. Sabemos lo único que importa saber: así como el señor Quijana, Quesada, Quijada o Quijano decidió ser ése a quien todos conocemos, don Pero Pérez decidió, simple, llana y grisáceamente, ser el cura.

mi oscura pluma de gramático, docta en nimiedades académicas y ajena a los trabajos de la espada

JORGE LUIS BORGES

Si los nombres pueden revelar aspectos inusitados de los objetos del mundo, también pueden erigir mundos de la nada. Don Quijote está plenamente consciente del "poder fundador del lenguaje, que instaura una realidad imaginaria, anima las cosas inertes, hace ver lo que aún no es, devuelve aquí lo desaparecido" (Benveniste: 27). Al discutir con el canónigo acerca de los libros de caballería, justo antes de comenzar su deleitosa narración del caballero que desciende hasta un suntuoso castillo donde hermosas damas lo sirven y agasajan, dice: “'hay mayor contento que ver, como si dijésemos, aqui ahora se muestra delante de nosotros un gran lago de pez hirviendo a borbollones [...]?" (I, 50: 509). A un lado de Sancho Panza, puebla de innumerables ejércitos el polvo con el solo poder de la palabra: "fue nombrando muchos caballeros de uno y del otro escuadrón que él se imaginaba, y a todos les dio sus armas, colores, empresas y motes de improviso... ¡Válame Dios, y cuántas provincias dijo, cuántas naciones nombró...!” (I, 18: 158-160). Ambos pasajes parodian, una vez más, los lugares comunes de los li- 
bros de caballerías y la epopeya (con sus catálogos extenuantes), pero van mucho más allá de eso.

El narrador puede respingar por el hecho de que don Quijote, enloquecido, vea "en su imaginación lo que no veía ni había", pero el caso es que el canónigo y los lectores quedamos como Sancho: "colgados de sus palabras". Dudamos de los sentidos, atendemos a las palabras y vemos desfilar nítidamente a Pentapolín del Arremangado Brazo, a Micocolembo, a Timonel de Carcajona, y relumbrar ese escudo sobre el cual retoza un gato dorado, a la sombra de las letras del "Miau". La palabra materializa aquello que convoca en otro nivel de la realidad.

La voluntad de nombrar el polvo, se pregunta Salinas (1958/2005), “¿no es idéntica a la del poeta?” Añadiría: idéntica a la de todo escritor y aun el principio de toda literatura. Qué burdo sería que el polvo no lo levantara el marchar de los ejércitos. Don Quijote exige un poco más de la realidad, como el escritor que de hecho es. Recordemos que, antes de enloquecer, tenía "el más delicado entendimiento que había en toda la Mancha" (I, 5: 59) y que "muchas veces le vino el deseo de tomar la pluma y dalle fin" a la Historia de Belianís de Grecia, empresa de la que habría salido airoso "si otros mayores y continuos pensamientos no le estorbaran" (I, 1:29).

Pudo no habernos legado esa conclusión del Belianís pero otras piezas fue dejando caer en el camino de sus andanzas, con las que podríamos armar sus Obras completas, en prosa y en verso. Más armado de palabras que de hierro, al salir de su casa por vez primera, antes que cualquier otra cosa, don Quijote describe el amanecer mitológico con que, elucubra, dará principio la jornada del libro que narrará sus aventuras: "Apenas había el rubicundo Apolo..." (I, 2: 35). No olvidemos tampoco ese libro de caballerías en miniatura que nos pinta en el capítulo 21 de la Primera parte: "antes que se llegue a ese término es menester andar por el mundo... buscando las aventuras". Sorprendidos, al leer las décimas del caballero, podemos decir con Sancho: "Luego ¿también [...] se le entiende a vuestra merced de trovas?" (I, 23:214).

Los episodios en los que acude a su lanzón y su espada suelen culminar con don Quijote en el suelo, apaleado o apedreado, o con la pierna de algún otro despedazada bajo una mula o con las espaldas abiertas por los latigazos. Por eso es de notar el episodio en que don Quijote logra 
calmar con sus solas palabras la pendencia entre el ventero y los huéspedes que, aprovechando una trifulca, pretendían salir desapercibidos, sin pagar: "Ya a esta sazón estaban en paz los huéspedes con el ventero, pues por persuasión y buenas razones de don Quijote, más que por amenazas, le habían pagado todo lo que él quiso" (I, 44: 463). Tímido, de puntitas, éste apenas asoma la frente sobre los pintorescos pasajes que se atiborran en la novela. A mi ver, se trata de una de las pocas victorias del hidalgo a lo largo de la narración, de un tuerto plenamente desfecho: no hay sangre, ni costillas pulverizadas, tan sólo la limpia y diplomática restitución del orden. Las palabras pueden volver un verdadero caballero andante, un don Quijote de la Mancha, incluso, al viejo hidalgo.

Al igual que su afán por buscar otros nombres a los nombres, los personajes de la obra comparten con don Quijote la plena conciencia del poder de la palabra para convocar lo enunciado. "No parece sino que ahora la veo", recuerda el cabrero al hablar de Marcela (I, 12: 106); "No la conocí yo - dice Sancho a propósito de Torralba- pero quien me contó este cuento me dijo que era tan cierto y verdadero, que podía bien, cuando lo contase a otro, afirmar y jurar que lo había visto todo" (I, 20:179).

También comparten con el protagonista el gusto inagotable por contar historias y algunos, de vivir en ellas, vestidos de pastores y de princesas. En el Quijote, incluso los personajes dentro de las historias que cuentan los personajes cuentan sus propias historias y las viven: he ahí la actuación de Camila en el "Curioso impertinente" (I, cap. 34). Este caleidoscopio delirante de narraciones va creando "un paisaje hecho de palabras y de imaginación que se superpone, hasta abolirlo por momentos, al otro, ese paisaje natural" (Vargas Llosa: XVIII): los nombres de los ejércitos se superponen al polvo.

Quizá don Quijote, ese hidalgo que una mañana decidió, frente a sus establos deplorables, volver a nombrar el mundo, no sea un magnífico escritor pero es un lector atento que conoce los giros, las fórmulas, los lugares comunes y, lo más importante, sabe transmitir a los otros, al grado de dejarlos atónitos, su propio gusto por los libros de caballerías. Pero quiso ser Aquiles y no Homero. En su caso, "una versión muy personal de la mimesis aristotélica" (Avalle-Arce 1976/2002), el conocido binomio de vida y obra cobra pleno significado. Así como Borges no pudo sino empuñar la pluma, don Quijote decidió escribir con la espada. Afor- 
tunadamente para nosotros, legó la tarea de narrar sus aventuras a Cervantes, ese "sabio encantador" que, nos consta, es mejor narrador que él.

\section{BIBLIOGRAFÍA}

Avalle-Arce, Juan Bautista. "La vida como obra de arte", en Don Quijote como forma de vida, Biblioteca Virtual Miguel de Cervantes, 1976/2002, en línea: $<$ http://www.cervantesvirtual.com/obra-visor/don-quijote-comoforma-de-vida--0/html/ff6f21 e6-82b1-11df-acc7-002185ce6064_25. html\#I_12_> [Fecha de consulta: 8 de mayo de 2015].

Ayala, Francisco. "La invención del Quijote", en Miguel de Cervantes, Don Quijote de la Mancha, edición y notas de Francisco Rico. Lima: Real Academia Española/Asociación de Academias de la Lengua Española, 2004: XXIX-XLIII.

Benveniste, ÉmiLe. "Ojeada al desenvolvimiento de la lingüística", en Problemas de la lingüistica general, vol. I. México/Madrid: Siglo XXI: 1971/1997: 20-32.

Cervantes, Miguel De. Don Quijote de la Mancha, edición y notas de Francisco Rico. Lima: Real Academia Española/Asociación de Academias de la Lengua Española, 2004.

FrenK, Margit. Cuatro ensayos sobre el 'Quijote'. México: Fondo de Cultura Económica, 2013.

Salinas, Pedro. "El polvo y los nombres", en José Montero Reguera, Antología de la crítica sobre el 'Quijote' en el siglo $\mathrm{XX}$, Centro Virtual del Instituto Cervantes, 1958/2005. En línea: <http://cvc.cervantes.es/literatura/ quijote_antologia/salinas.htm $>$ [Fecha de consulta: 15 de mayo de 2015].

SPITZER, Leo. "Perspectivismo lingüístico en el Quijote", en José Montero Reguera, Antología de la crítica sobre el Quijote en el siglo XX, Centro Virtual del Instituto Cervantes, 1948/2005. En línea: <http://cvc.cervantes. es/literatura/quijote_antologia/spitzer.htm\#npas> [Fecha de consulta: $15 \mathrm{de}$ mayo de 2015].

VARgas Llosa, Mario. "Una novela para el siglo Xxi”, en Miguel de Cervantes, Don Quijote de la Mancha, edición y notas de Francisco Rico. Lima: Real Academia Española/Asociación de Academias de la Lengua Española, 2004: XIII-XXVIII. 